\title{
Optimizing mine production scheduling for multiple destinations of ore blocks
}

\author{
M. Jamshidi ${ }^{1}$ and M. Osanloo ${ }^{2 *}$ \\ ${ }^{I}$ Department of Mining and Metallurgy, Amirkabir University of technology, Tehran, Iran \\ ${ }^{2}$ Department of Mining and Metallurgy, Amirkabir University of technology, Tehran, Iran
}

Received: 15 March 2017

Revised: 12 December 2017

Accepted: 31 Janurary 2018

DOI: http://dx.doi.org/10.3329/bjsir.v53i2.36670

\begin{abstract}
In multi-element deposits, the quality of mining production is impressed by multiple inter-correlated elements and there is an essential task of blending the run-of-mine materials in such a way that the resulting mix meets the required specifications. Generally, blending plans are established based on one destination for products, but blending allows mixing different material and achieving to a wide range of quality. Then, it is possible to consider multiple destinations for mine product. In this paper, a Mixed Integer Programming model is developed for production scheduling of an iron ore mine regarding four different destinations. As the iron ore mines could be considered as direct-shipping ore, in this model, the effect of enrichment unit is investigated by six different scenarios based on different cut-off grades. Performing a sensitivity analysis on cut-off grades would distinguish whether the block should go to enrichment unit before blending or participate in blending plan directly. The result of running the model in the case of four destinations is compared to the case that only one destination is considered. The highest NPV in the case of four destinations is about $25 \%$ more than the highest NPV of the case that only one destination is considered.
\end{abstract}

Keywords: Iron ore; Blending; Multi-Destination; Production scheduling; MIP

\section{Introduction}

The efficiency of steel factories as the main consumer of iron ore heavily depends on the chemical and physical properties of the raw materials. Therefore, the characteristics of the required iron ore are designated in the related contracts. In this regard, the aim of mine planners is to schedule of mine production in a way that the final product be as much as possible compatible with the dictated characteristics in the contract.

The production scheduling determines the time of excavation and the destination of each block and deals with a set of operational and physical constraints, such as mining and processing capacities, mineable ore deposit, slope and access constraint. In most mining operations, especially in iron ore mines, another constraint that should be taken into account is the homogeneity of the product, to do this, blocks with different characteristics, blend together to meet the required quality. Additionally, blending is necessary to control wide fluctuations in the mill feed, which may decrease metallurgical recovery and consequently increases processing costs (Peralta 1991). Blending can be defined as a methodical, systematic process of combining a variety of materials into a uniform mass (Chanda and Dagdalen 1995). Based on the tonnage-grade curve of an iron ore deposit, it is possible to extract raw material with different properties and has a range of products. The value of the produced material depends on the grade of Fe and other elements, which should be achieved according to destination (customer) requirements.However, it is important to make sure that all the possibilities are considered in production scheduling of the reserves extraction to achieve the highest NPV. In iron ore mines, the production planning could be constructed not just with a single product, but taking into account that a block can be blended with other blocks to make one of many alternative final products (Fig. 1). In this case,blending operation should satisfy all customer'sdemands.Concerning these requirements, the suitable destination for each block is determined in accordance with block characteristics and destination blending criteria.It should be noted that the value of each block, depends on the selected destination (customer). 


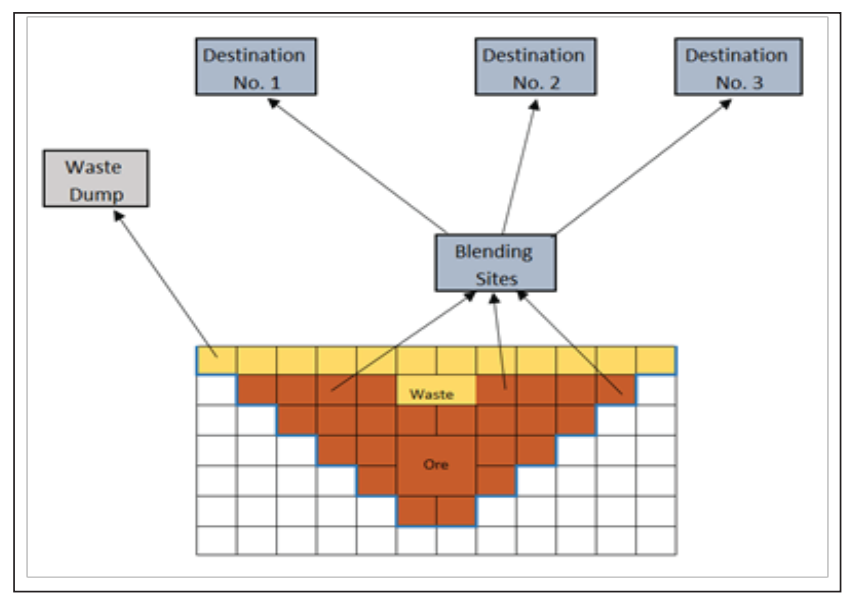

Fig. 1. Blending sites and possible destinations

Several attempts have been made in mine production planning by considering blending constraint. Fraser, presented the first computer-based technique, which was applied for blending in mine planning for coal shipments (Chanda and Dagdalen 1995). Peng et al. used Linear Programming (LP) for production scheduling in coal mines with the aim of minimizing the production costs (Peng 1979). Fytas and Calder introduced a combination of simulation for long-term production and LP for short-term production planning with the overall objective of maximizing profit and meet certain productivity (Fytas 1986). White and Olson (1986) used an LP model to optimize dispatching fleet in an open pit mine in line with blending constraint. In addition, Sundar and Acharya (1995), Temeng et al. (1997), Caccetta, and Giannini (1986) used LPto optimize the production scheduling problem by considering blending constraint. Smith used stochastic programming for production scheduling in a uranium mine (Smith 2001). Gholamnejad et al. (2008) used MIP for production scheduling by accountinggrade uncertainty. The grade distribution function in each block is used as a stochastic input tooptimize the model. Dimitrakopoulos and Ramazan (2008) presented a model based on stochastic planning. The objective of this model, is to maximize the present net value and minimizing distraction from production plan. The presented model was evaluated for two deposits of gold and copper. Rahman and Asad (2010) presented a model for short-term production scheduling in a lime mine with the objective of minimizing production costs.

Other researchers such as Zuckerberg et al. (2011), Askari-Nasab et al. (2011), Rahmanpour and Osanloo (2012) have used Mixed Integer Linear Programming (MILP) in production scheduling of open pit mines considering blending constraint. Kumral and Dowd (2002), and Kumral
(2003) used multi-objective simulated annealing for short-term mine production scheduling and solving a mineral blending problem. Samanta and Bhattacherjee (2005), Denby et al. (1991) used a Meta-heuristic approach for grade control planning in open pit mines. Souza et al. (2010) introduced a heuristic model for short-range production scheduling in open pit mines considering blending requirements. Asad (2011) used a heuristic approach to long-range production planning of a cement quarry when blending constraintswere taken into account. Additionally, other researchers such as Vujic et al. (2011), Sari and Kumral (2015), Montiel and Dimitrakopoulos (2015), Goodfellow and Dimitrakopoulos (2016), Jelvez and et al. (2016) and Lamghari and Dimitrakopoulos (2016), used heuristic and meta-heuristic approaches to solving production scheduling. Smith and Wicks (2014) use a mixed-integer program (MIP) that maximizes recovered copper and constraints including shovel, extraction and processing capacities, and blending were taken into account.

Eivazy and Askari- Nasab (2012) account for blending stockpiles with the objective of minimizing mining cost, processing cost, waste rehabilitation cost, re-handling cost and hauling cost.L'Heureux et al. (2013) present a mixed integer programming model for production planning in open-pit mines. considering operational activities. Matamoros and Dimitrakopoulos (2016), developed a stochastic integer programming model. The formulation simultaneously optimizes fleet and mining considerations, production extraction sequence and production constraints.

Jamshidi and Osanloo (2016) presented a linear model for determining block economic value based on multiple existing elements in the orebody considering blending effect. represented a new approach for determining the optimum cut-off grade in multi-product open pit mines through using the imperialist competitive algorithm. represent a model to determine the push backs in two-element deposits, considering the effect of two elements in the block economic value.

Rahmanpour and Osanloo (2017) developed a fuzzy linear programming model to provide a set of options for the mine plan considering blending. These blending options are treated as portfolios. Then a model for the optimal selection of a portfolio is introduced. The objective of the model is to maximize the expected return of the portfolio.

All these methods have some advantages, butnone of them has considered the possibility of multi destination for ore blocks. Therefore, in this study, a new mathematical model is 
developed to investigate the effect of having more than one destination on production planning. This model optimizes production planning based on the requirements of each destination with the objective of maximizing NPV incorporated with satisfying blending demands of each destination.

\section{Materials and methods}

Iron ore is the most widely used metallic ore in the world. Total produced iron ore in 2015 is about 3,320 million tons (USGS 2016) and the primary usage of iron ore is to the manufacturing of steel. There are different kinds of iron ore mineral, and the ores are usually rich in iron oxides. Generally, iron ore deposits have a high content of

Table I. Acceptable limit of impurities that enter into the steel compound (Towhidi and Vaghar 1998)

\begin{tabular}{|c|c|c|}
\hline Type & $\begin{array}{c}\text { Acceptable limit } \\
(\%)\end{array}$ & Effect of excessive compounds \\
\hline $\mathrm{Cu}$ & 0.006 & Reducing mechanical properties \\
\hline$S n$ & 0.01 & Reducing mechanical properties \\
\hline $\mathrm{Cr}$ & $0.01-0.05$ & Sharply reduce the fluidity \\
\hline$V$ & $0.01-0.05$ & Sharply reduce the fluidity \\
\hline Mo & $0.02-0.05$ & Sharply reduce the fluidity \\
\hline
\end{tabular}

Fe, so this kind of ore has a selling opportunity as a Direct Shipping Ore (DSO). This means that, due to its high Fe content, such minerals may be mined and extracted with a relatively simple crushing and screening process to be delivered to the customers. Payment for the iron ore is based upon consistent grade, not only in its iron content but also in its content of the other elements. In terms of lithology, these elements can be divided into two groups as follows:

\section{A- Useful Elements}

The main components in this group are lime and manganese compounds. The existence of lime causes a reduction in the flux requirement and consequently decreases cost and energy consumption. The presence of manganese compounds increases the economic value of the ore. Manganese removes sulfur, and it prevents the steel from cracking (Towhidi and Vaghar 1998). In addition, manganese enters the cast iron or steel compounds and improves its quality.

\section{Undesirable elements}

There are two kinds of impurities in this group, the first one are those that enter into the steel compound and compromise the quality of the final product, these are copper $(\mathrm{Cu})$, tin (Sn), chromium (Cr), vanadium (V) and molybdenum (Mo). The acceptable limit of these impurities for $\mathrm{Fe}$ grade about $60 \%$ is shown in Table I.

The second group of impurities are zinc $(\mathrm{Zn})$, lead $(\mathrm{Pb})$, titanium dioxide $\left(\mathrm{TiO}_{2}\right.$.), sodium oxide $\left(\mathrm{Na}_{2} \mathrm{O}\right)$, potassium oxide $\left(\mathrm{K}_{2} \mathrm{O}\right)$, arsenic $(\mathrm{As})$, phosphorus $(\mathrm{P})$, sulfur $(\mathrm{S})$, chlorine $(\mathrm{Cl})$ and fluorine $(\mathrm{F})$. This group of impurities causes trouble in the steel production process or has emissions that are associated with environmental pollution. The acceptable grade of these impurities for Fe grade about $60 \%$ is shown in Table II.

Table II. Acceptable limit of impurities that cause disruption in the production process (Towhidi and Vaghar 1998)

\begin{tabular}{|c|c|c|}
\hline Type & $\begin{array}{l}\text { Acceptable } \\
\text { limit (\%) }\end{array}$ & $\begin{array}{c}\text { Effect of excessive } \\
\text { compounds }\end{array}$ \\
\hline$Z n$ & $0.02-0.05$ & Disturb refractory materials \\
\hline $\mathrm{Pb}$ & $0.02-0.05$ & $\begin{array}{l}\text { Disturb refractory materials } \\
\text { and Increase the volume of } \\
\text { slag }\end{array}$ \\
\hline $\mathrm{TiO}_{2}$ & $0.1-0.6$ & Thickening of the slag \\
\hline $\mathrm{Na}_{2} \mathrm{O}+\mathrm{K}_{2} \mathrm{O}$ & $0.1-0.2$ & Disturb refractory materials \\
\hline As & 0.005 & Toxic emissions \\
\hline$P$ & $0.1-0.2$ & $\begin{array}{l}\text { React with the oxygen and } \\
\text { form acidic oxides and also } \\
\text { reduce cast iron quality }\end{array}$ \\
\hline$S$ & $0.1-0.2$ & $\begin{array}{l}\text { React with the oxygen and } \\
\text { form acidic oxides and also } \\
\text { reduce cast iron quality }\end{array}$ \\
\hline $\mathrm{Cl}$ & $0.001-0.006$ & $\begin{array}{c}\text { Corrosion in metallic } \\
\text { facilities in chimneys and } \\
\text { toxic emissions }\end{array}$ \\
\hline$F$ & $0.001-0.002$ & $\begin{array}{c}\text { Corrosion in metallic } \\
\text { facilities in chimneys and } \\
\text { toxic emissions }\end{array}$ \\
\hline
\end{tabular}


The production planner of the mine, should schedule the mine production and the blending of blocks in a manner that not only the grade of desirable elements satisfies the demands but also the grade of undesirable elements be lower than eligible limits.

In this regards, the model of blending for production scheduling is developed for multi-element deposits that consider the grades of different elements and also having more than one destination for final product of the mine. In this model, the number of blending plans is proportional to the number of destinations, and each extracted block is controlled byblending plans. Ifthe quality of the block satisfies only one of the plans, the revenue of mentioned block will be calculated and consequently the destination and time of block extraction will be declared. However, if it is possible to use the block in more than one blending plan, then the destination, which maximizes the income, will select as the suitable destination for the block.

In DSO mines, there is the possibility of using a simple processing operation to increase the metal content of the blocks, hence, as the schematic path of the blocks has been illustrated in Fig. 2, an Enrichment Unit (EU) has been considered to make an incremental role for extracted ore in $\mathrm{Fe}$ content. But it is important to specify which block should be sent to EU and which one could be used in blending directly. In this regard, six scenarios are taken into account, in the scenarios the cut-off grade (COG) is the criterion to send the block to EU or not. For each scenario of running the model, theblocks with Fe content lower than COG will be sent to the EU and consequently the output of this unit will be used in blending plans. On the other hand, the blocks that have $\mathrm{Fe}$ content more than COG sent to blending sites directly.

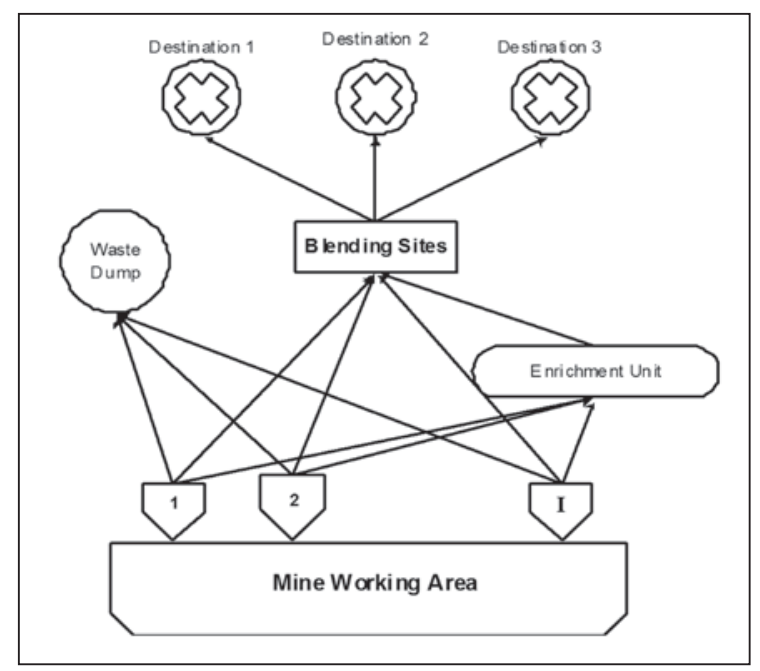

Fig. 2. Schematic path of blocks in the model
For the blocks that are forwarded to EU, increasing Fe content will lead to decrease weight of the blocks. Therefore, a new factor, named Loss Factor, is introduced to calculate differences between input tonnage and output tonnage (Equation. 1).

$$
L F=I T-O T
$$

Where:

\section{LF: Loss Factor \\ IT: Input Tonnage \\ OT: Output Tonnage}

By calculating the loss factor, it is possible to determine the relationship between inputgrade, output grade and loss factor. For this purpose, a multi-variable regression between $\mathrm{g}_{1}, \mathrm{~g}_{2}$, and LF is required to determine coefficientsa, $b$ and $d$ in Equation. 2. To calculate and determine the output grade of the EU, the regression between $g_{1}$ and $g_{2}$ is required as well.

$$
L F=a \times g_{1}+b \times g_{2}+d
$$

Where:

$$
\mathrm{g}_{1}: \text { grade of input material }
$$

$\mathrm{g}_{2}$ : grade of output material

$\mathrm{a}, \mathrm{b}$ and $\mathrm{d}$ : coefficient

Once the Equation. 2 was solved, the model should be run to determine the best production plan with the highest NPV by taking account required blends for different destinations.

\section{Optimization model}

In this model, a procedure has been defined to achieve required blending based on the production of an iron ore mine without considering any stockpile. As results of this model, we expect to determine the best destination/customer of all extracted blocks in each time.

The block properties are evaluated based on the destination criteria. In this regard, the economic value of each block is calculated for each destination and is checked to see which destination requirements meet the block blending. For the blocks that are possible to use only in one blending plan, other constraints such as slope and capacity constraint are checked and the destination and extraction period is demonstrated if the block meets the constraints. However, the destination maximizing the NPV is selected as the final destination for ore block if the block characteristics allow to use it in some of the blending plans. 
In fact, the material that extracted from the mine, have different content of Fe, S and $\mathrm{P}$ percent. Therefore, the model considers blend requirements in each separate destination and then the blocks properties are checked to contribute to blending. In each period, the blocks that could be mixedto satisfy the destination criteria and create the maximum profit will be chosen.

The objective function of the model (Equation. 3) is defined tomaximize the discounted profits and minimize the deviation between produced blend and requested blend in different destination along the mining periods. Constraints of this model consist of mining capacity, destinations capacities, slope constraint and maximum/minimum eligible grade for elements. The procedure of mentioned model optimization is presented as below:

$$
\begin{aligned}
& \text { Maximize } Z=\sum_{t \in T} \sum_{b \in B} \sum_{d \in D} x_{b}^{t d}\left(I_{b}^{t d}-C_{b}^{t d}\right) \\
& \sum_{b \in B} x_{b}^{t d}\left(g_{b}^{F e}-g_{\min }^{F e}\right) \geq 0 \forall d \in D . t \in T \\
& \sum_{b \in B} x_{b}^{t d}\left(g_{M a x}^{F e}-g_{b}^{F e}\right) \geq 0 \forall d \in D . t \in T \\
& \sum_{b \in B} x_{b}^{t d}\left(g_{\text {Max }}^{S}-g_{b}^{S}\right) \geq 0 \quad \forall d \in D . t \in T \\
& \sum_{b \in B} x_{b}^{t d}\left(g_{\text {Max }}^{P}-g_{b}^{P}\right) \geq 0 \quad \forall d \in D . t \in T \\
& \sum_{t \in T} \sum_{d \in D} x_{b}^{t d}=1 \quad \forall b \in B \\
& \left\{\sum_{b \in B} \sum_{d \in D}\left(x_{b}^{t d} \times X_{b}\right) \leq M_{c} \quad \forall t \in T\right. \\
& \sum_{b \in B}\left(x_{b}^{t d} \times O_{b}^{t d}\right) \leq D_{c} \quad \forall d \in D . \quad t \in T \\
& \sum_{d \in D} x_{b}^{t d} \leq \sum_{t \leq t} \sum_{d \in D} x_{b^{\prime}}^{t d} \forall b \in B . \quad t \in T
\end{aligned}
$$

Notation:

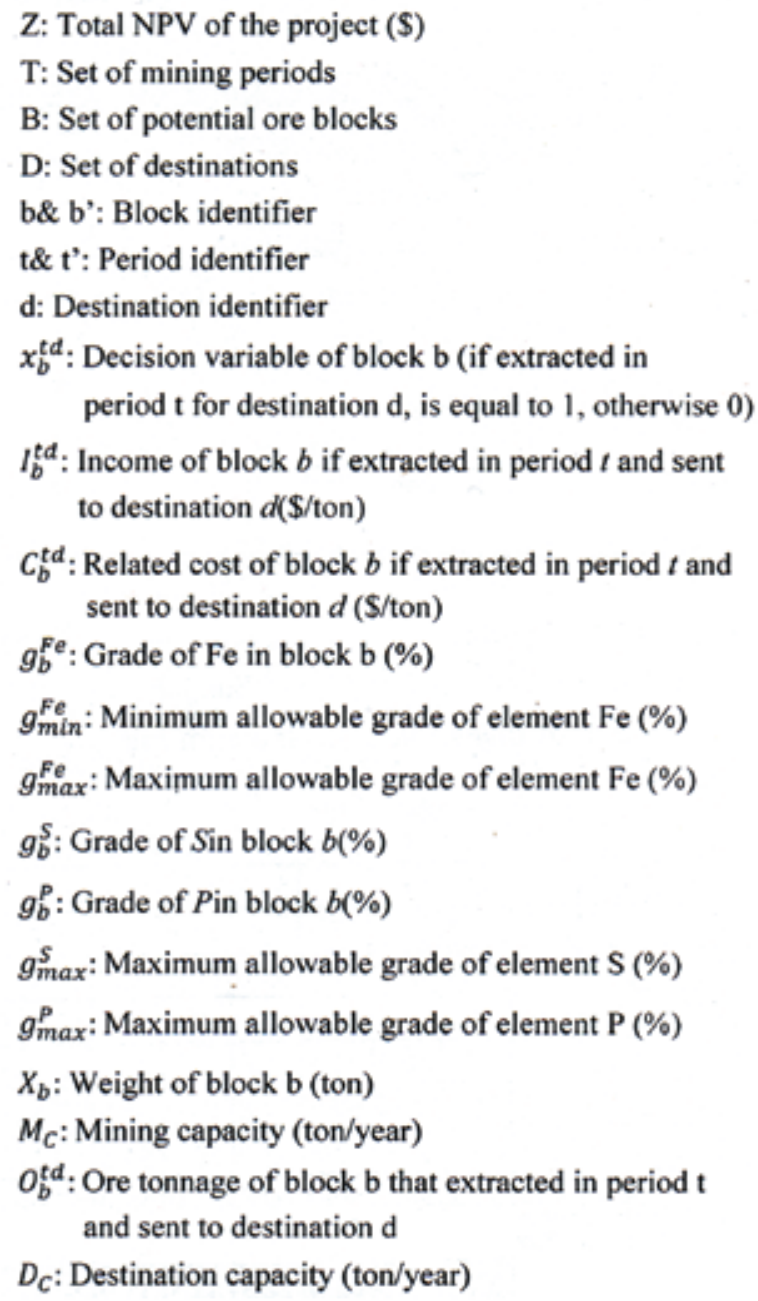

Each destination includes a criterion to accept the Fe in the minimum grade. If the Fe content of the mine product fails to satisfy the criterion, the customer has the right for rejection. Therefore, it should be checked whether the mine product can meet the minimum acceptable grade of the destination. In addition, the maximum grade of Fe should be checked due to the limitation in the contract of selling the raw material and the saving opportunity to blend the high and low grade material to obtain more valuable product. In Equations 4 and 5 , the minimum and maximum allowable $\mathrm{Fe}$ grade, are checked based on each destination blending criteria.

The maximum acceptable grades of $\mathrm{S}$ and $\mathrm{P}$ are controlled in Equations 6 and 7 as well. The existence of the undesirable elements if the limit is exceeded, can impose some penalties. Thus, it is important to check the grade of these elements in the mine product and maintain them as low as possible with respect to the acceptable limits. 
Equation.8is created to ensure that an extracted block isused onlyfor a particular destination in production periods and each block extracted once. The block is used in the production scheduling several times without considering this constraint. Therefore, some constraints are required to assure that the block has been extracted once. Mining capacity, including produced ore and waste during production is controlled in Equation 9.

The destination capacity is another constraint by which the total block material sent to each destination in different periods should not exceed the destination capacity, therefore another constraint that must be taken into account is the destinations capacities. Equation.10 check this criterion. In each period, the upper blocks should be extracted prior to planned blocks; therefore, Equation. 11 is created to represent related slope and priority constraints that allow underlying blocks to be mined only after blocks on top of them.

\section{Solving the model}

The block model as the input data should be consisting of different elements containing main mineral and the inter-correlated elements such as $\mathrm{S}$ and $\mathrm{P}$. The presented model is applied on an east-west cross-section of the Tapeh Qermez (TQ) iron ore mine in the north east of Iran in Sangan iron ore mine complex. The input, block model of elements $\mathrm{Fe}, \mathrm{S}$, and $\mathrm{P}$ of this section are shownin Fig. 3 up to Fig. 5.

In this model, four different destinations for mine products are taken into consideration with specific blending characteristics. The specification of required iron ore, related costs and income for each destination are shown in Table III. Another destination that is considered in the model is waste dump (destination No. 5) that in addition to waste blocks, the rejected blocks by blending plans, are dumped in waste dump too, these blocks should be removed in order to access to the

\begin{tabular}{|c|c|c|c|c|c|c|c|c|c|c|c|c|c|c|c|c|c|c|c|c|}
\hline & & & & & & & & & & & & & & & & & & & & \\
\hline & .0 & & & & & & 3.7 & & & .7 & & .6 & & & .0 & & 5.0 & & 52.5 & \\
\hline & & & & & & & & & & & & & & & & & & & & \\
\hline & & & & & & & & & & & & & & & & & & & & \\
\hline & 1.2 & .8 & .2 & .8 & .0 & & 2.6 & & 52.5 & 55.0 & 60.8 & 55.0 & & .5 & 52.5 & & 60.8 & & 52. & \\
\hline & 52.5 & & & & & & & & 52.5 & 55.0 & & & & & & & & & & \\
\hline & 52.5 & & & & .5 & .5 & 55.2 & 9.6 & 59.0 & 60.8 & & 52.6 & & & 59.0 & & 55 & & 52.5 & 52. \\
\hline & 55.0 & & & & & & & & 55.0 & 59.6 & & & & & & & & & & \\
\hline & 55.2 & & & & & 26 & 52.5 & 25 & 61.0 & 58.0 & 52. & 52.5 & & & 50 & 52. & 55 & 55 & 52 & 52. \\
\hline & 52.5 & 7.3 & 54.3 & 57.5 & 60.8 & .2 & 58.8 & 54.5 & 60.2 & 60.4 & 55.2 & 55.6 & & & 52.6 & [2Z.3 & | 52.5 & 5.4 & 50.1 & 52 \\
\hline & 55 & & & & & & 550 & & 51 & & & & & & & & & 53 & 55 & \\
\hline
\end{tabular}

Fig. 3. The grade of $\mathrm{Fe}$ in blocks

\begin{tabular}{|c|c|c|c|c|c|c|c|c|c|c|c|c|c|c|c|c|c|c|c|c|}
\hline & 1 & & & & & & & & & & & & & & & & & & & \\
\hline & & 0.213 & & & & & & & & & 0.025 & & & & 0.062 & & & & & \\
\hline & 45 . & 21 & & & & & & & 0.328 & 0.362 & 0.368 & 120 & & 0.360 & 0.382 & & & & & \\
\hline & & & & & & & & & & & & & & & & & & & & \\
\hline & 10 & & 486 & 0.367 & 677 & 120 & 0.378 & 383 & 430 & 366 & 0.392 & 497 & & & 0.367 & 423 & +20 & 10.3 & 33 & \\
\hline & & 60 & 249 & & & & & & 024 & & & & & & & & & & 0 & \\
\hline & 0.396 & 354 & 0.451 & 0.121 & 145 & .109 & 0.159 & 0.430 & 0.467 & 0.468 & 0.328 & 0.362 & 0.368 & 0.420 & 0.485 & 0.305 & 249 & & 0.045 & \\
\hline & .248 & 209 & 024 & 0.105 & 256 & 210 & .025 & 106 & .099 & 0.063 & 0.062 & .070 & 0.028 & 3 & 0.396 & 0.354 & 0.451 & 0.12 & 0.14 & \\
\hline & 0.1 & 30 & 467 & 0.468 & 0.328 & 362 & 0.249 & 0.213 & 0.045 & 0.105 & 0.248 & 0.209 & 0.024 & & 0.256 & 0.219 & 0.025 & & 0.09 & \\
\hline & & & & 0.315 & 0.396 & .354 & 0.451 & & & & & & & & & & & & & \\
\hline & $M$ & 0.105 & 0.256 & 0.219 & 0005 & 106 & 000 & 0.063 & 0.062 & 0070 & 0008 & 315 & 030 & 23 & 0451 & 011 & 0 & 010 & 0.15 & \\
\hline
\end{tabular}

Fig. 4. The grade of Sin blocks 


\begin{tabular}{|c|c|c|c|c|c|c|c|c|c|c|c|c|c|c|c|c|c|c|c|c|}
\hline & 1 & & & & & & & & & & & & & & & & & & & \\
\hline & 0.249 & 0.213 & & & 0. & & & & 56 & & 0.025 & & & & & & & & & \\
\hline & 451 & 121 & & & & & & & & 652 & .663 & 051 & & 49 & & 810 & & & & \\
\hline & 811 & & & & & & 111 & & & & & & & & & & & & & \\
\hline & 80 & & & & & & & & & & & & & & & & & & & \\
\hline & .814 & 0.649 & 0.249 & .213 & .045 & .105 & 0.248 & 0.209 & 0.024 & 0.105 & 0.256 & 0.219 & 0.025 & 0.106 & 0.099 & 0.063 & 0.06 & 0.0 & 00 & 56 \\
\hline & 396 & 0.637 & 0.451 & 121 & & 109 & 0.15 & 10.430 & |0.467| & 0.468 & 0.591 & 0.65 & 1.6 & 1.051 & $0.8^{\prime}$ & 0.5 & & 0.2 & 0.0 & \\
\hline & 0.248 & 0.209 & 0.024 & & & & 0.025 & & & 0.063 & 0.062 & & & & & & & & & \\
\hline & .159 & 0.430 & 0.467 & & 591 & 652 & 0.249 & 0.213 & 0.045 & 0.105 & 0.248 & 0.20 & 00 & 0.10 & 0.25 & 0.2 & & 0.1 & 0.0 & \\
\hline & 062 & 0.070 & 0.028 & 566 & 0.396 & .637 & 0.451 & 0.121 & 0.145 & 0.109 & 0.159 & 0.43 & & 0.46 & 0.249 & 0.21 & & 0.1 & 0.24 & \\
\hline & & & & & & & & & & & & & & & & & & & & \\
\hline
\end{tabular}

Fig. 5. The grade of Pin blocks

lower blocks. The cost of extraction and sending blocks to waste dump considered to be $5 \$$ ton. Six scenarios were considered for running the model. In the first scenario, the model was run without sending any block to EU.In other scenarios, the effect of EU is investigated and scenarios have blending. The NPV if this scenario is 24,199,054 \$. In other scenarios, the use of EU (Magnetic Separation) is investigated for TQmine. To determine the effect of the EU on tonnage and grade of materials, the monitored data of this unit are used. The monitored data related to input and out put

\section{Table III. Destinations blending specification}

\begin{tabular}{|c|c|c|c|c|c|}
\hline \multirow{2}{*}{ Parameter } & \multirow{2}{*}{ Unit } & \multicolumn{3}{|c|}{ Destinations } & \multirow[b]{2}{*}{ No. 4} \\
\hline & & No. 1 & No. 2 & No. 3 & \\
\hline Max grade of $\mathrm{Fe}$ & $\%$ & 62 & 60 & 58 & 56 \\
\hline Min allowed grade of $\mathrm{Fe}$ & $\%$ & 60 & 58 & 56 & 54 \\
\hline Max allowed grade of $\mathrm{P}$ & $\%$ & 0.2 & 0.2 & 0.3 & 0.3 \\
\hline Max allowed grade of S & $\%$ & 0.2 & 0.2 & 0.3 & 0.3 \\
\hline Income & (\$/ton) & 31 & 28.5 & 25 & 22 \\
\hline Costs & (\$/ton) & 13 & 12 & 12 & 13 \\
\hline Capacity & (ton/year) & 400000 & 300000 & 500000 & 300000 \\
\hline
\end{tabular}

been formed based on differentcut-off grades (COGs). First scenario; In this case, blocks characteristics are checked to be used in one of the four blending plans based on the natural properties of blocks. The result of this scenario is illustrated in Fig. 6. In this figure, each block containing two numbers, the upper one refer to selected destination for sending the block and the lower number shows the specific period allocated to block extraction. Running the model, in TQ mine without considering EU, the suitable destination for blocks are determined based on capacities and destinations required characteristics of the shown in Table IV. The relationship between input and output grades is determined by regression, (Equation. 11). Fig.7 illustrated the relationship between input and output grades.

$$
g_{2}=0.3358 g_{1}+40.853
$$

Multivariable regression between input, output grades and loss factor, is used to define the relationship between these parameters. The result of multi-variable regression is as 


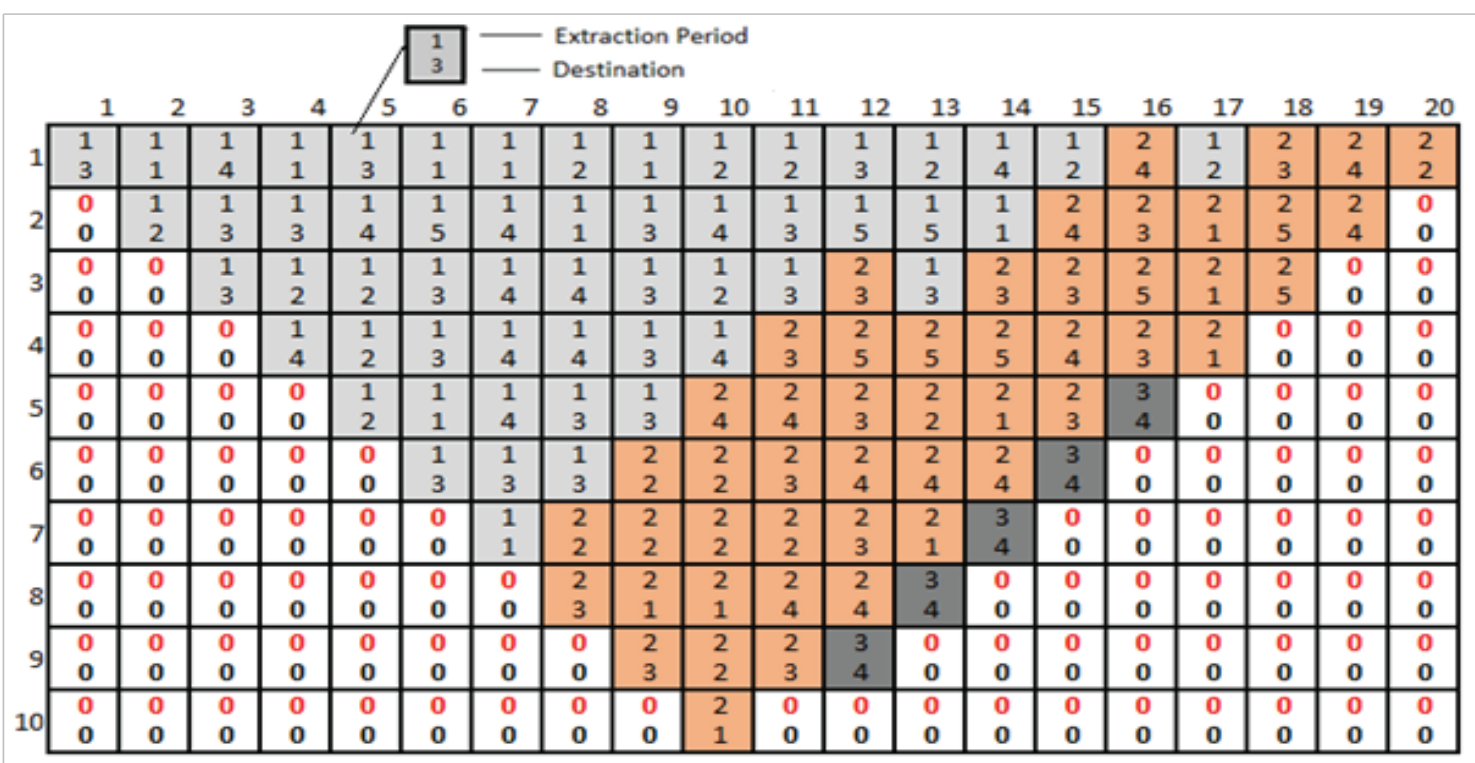

Fig. 6. The result of the model in the first scenario

Table IV. The input and output material of magnetic separator

\begin{tabular}{cccccccc}
\hline \multicolumn{2}{c}{ Input } & \multicolumn{2}{c}{ Output } & \multicolumn{2}{c}{ Input } & \multicolumn{2}{c}{ Output } \\
\hline Fe \% & Ton & Fe \% & Ton & Fe $\%$ & Ton & Fe \% & Ton \\
\hline 51.7 & 1393.5 & 57.8 & 1065.0 & 56.0 & 1447.1 & 59.9 & 1269.8 \\
52.2 & 1071.9 & 58.4 & 786.3 & 49.1 & 2036.6 & 57.1 & 1556.5 \\
56.4 & 1607.9 & 60.1 & 1228.8 & 56.1 & 1822.2 & 60.2 & 1546.2 \\
49.6 & 1487.3 & 57.5 & 1126.4 & 56.5 & 1554.3 & 60.1 & 1290.2 \\
50.6 & 1520.8 & 58.3 & 1325.3 & 47.5 & 1286.3 & 56.9 & 983.0 \\
53.2 & 750.3 & 59.1 & 573.4 & 50.7 & 2251.0 & 58.1 & 1720.3 \\
55.3 & 1339.9 & 59.0 & 1024.0 & 56.7 & 700.0 & 60.1 & 507.0 \\
55.3 & 1179.1 & 59.7 & 901.1 & 54.5 & 993.1 & 58.8 & 798.5 \\
53.1 & 1366.7 & 59.1 & 1043.2 & 55.1 & 1902.6 & 59.1 & 1698.3 \\
52.2 & 1554.3 & 58.4 & 1187.8 & 55.2 & 1301.3 & 59.3 & 1169.6 \\
50.9 & 857.5 & 57.8 & 655.4 & 53.4 & 1147.2 & 58.6 & 947.8 \\
47.3 & 1071.9 & 57.2 & 819.2 & 56.6 & 1259.9 & 60.1 & 912.7 \\
52.2 & 1393.5 & 57.9 & 1187.8 & 52.3 & 1189.9 & 58.1 & 862.0 \\
49.2 & 1500.7 & 57.1 & 1372.2 & 51.4 & 1329.9 & 57.8 & 963.4 \\
51.3 & 1715.0 & 58.3 & 1310.7 & 54.2 & 805.0 & 58.4 & 583.1 \\
54.5 & 1607.9 & 58.4 & 1228.8 & 50.1 & 700.0 & 57.8 & 507.0 \\
47.4 & 1073.0 & 57.6 & 815.2 & 52.2 & 840.0 & 58.8 & 608.4 \\
\hline & & & & & & & \\
\hline
\end{tabular}

Equation. 12.

$$
L F=-4.9 g_{1}+11.2 g_{2}-77.48
$$

By Equation.11 and Equation. 12, it is possible to calculate the grade and tonnage of the output material after EU. Five different COG swere taken into account to distinguish which blocks should be sent to the EU. The minimum and maximum Fe grade of blocks in TQ mine are 50 to 61 ; consequently, 52, 54, 56, 58 and 60 were considered as COGs.

Second scenario; in this scenario, COG is $52 \%$ and the blocks with a grade lower than $52 \%$ are sent to the EU. The output grade and tonnage of blocks are calculated using Equations.

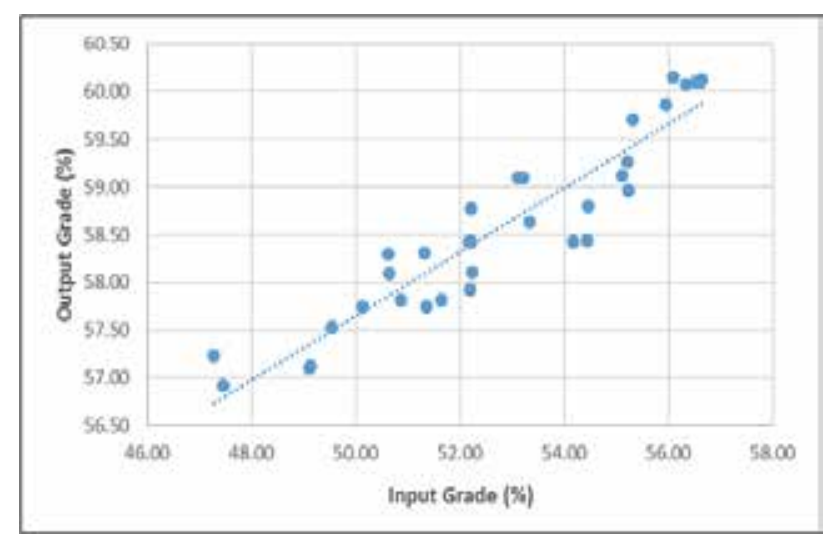

Fig. 7. The regression of input and output grades 
11 and 12 . In this scenario, when the COG is $52 \%$, all blocks with a grade lower than $52 \%$ are forwarded to the EU and the output tonnage and grade are determined. For example, for input tonnage and grade of 23787.5 tons and $51.84 \%$ respectively, the output grade and tonnage can be calculated by Equations. 11 and 12 as:

$g_{2}=0.3358 g_{1}+40.853=(0.335 \times 51.84)+40.853=58.26$

$L F=-4.9_{1}+11.2 g_{2}-77.48$

$L F=(-4.9 \times 51.84)+(11.2 \times 58.26)-77.48=321.016$

$O T=I T-L F$

$O T=23787.5-321.016=23466.4$

The output tonnage and grades of all blocks that sent to EU can be calculated in a similar way. The result of running the model for this scenario gives NPV equal to 25,222,842 \$. Third scenario; in this scenario, COG is 54\%. The blocks that have a grade lower than $54 \%$ forwarded to EU. The NPV, which achieved in third scenario,is 24,354,283 \$. In other scenarios, a COG is considered as an index to sending blocks to EU or uses that directly in blending. It means that the

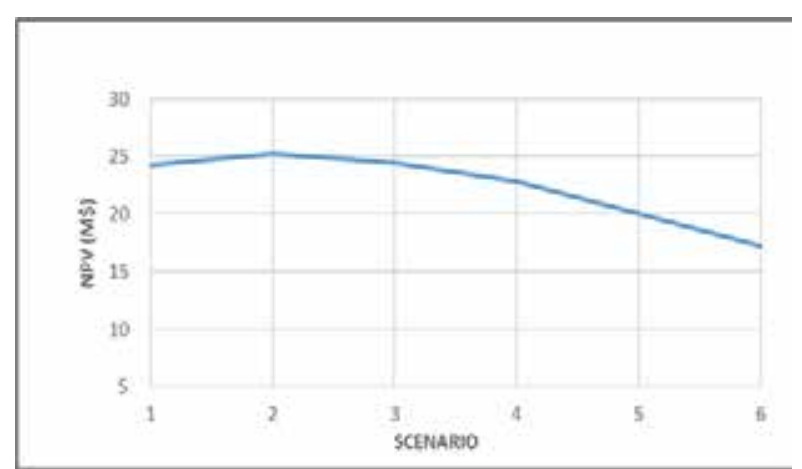

Fig. 8. NPV changes in different scenarios blocks with a grade lower than COG goes to EU and then the output of the EU used for blending.

The other scenarios, in glance, are as follows:

Fourth scenario; COG: 56\%, NPV: 22,801,444 \$.

Fifth Scenario; COG: 58\%, NPV: 19,979,767 \$.

Sixth scenario; COG: 60\%, NPV: 17,192,865 \$

Fig. 8 shows the changes of the total NPV of the project in all scenarios and Fig. 9 illustrates the result of the second scenario (the highest NPV), including extraction period (upper number) and thefinal destination for each block.

\section{Results and discussion}

As mentioned in the previous section, six scenarios were considered in running the model. The aim of these scenarios was to distinguish that, in which case, the maximum NPV of the operation will be achieved.

In this section to specify the effect of having more than one destination in production scheduling and also total NPV of the project, all the mentioned scenarios in the previous section have been implemented considering only one destination. In this case, the COGs are the same as the case of four destinations. To determine the appropriate destination for mine product, based on the average grade of Fe, one of the quotes of Table III that is more compatible with mine average grade, selected as the destination for sending the mine product. Table V, shows the scenarios of this case.

The production planning of this case is done in a similar

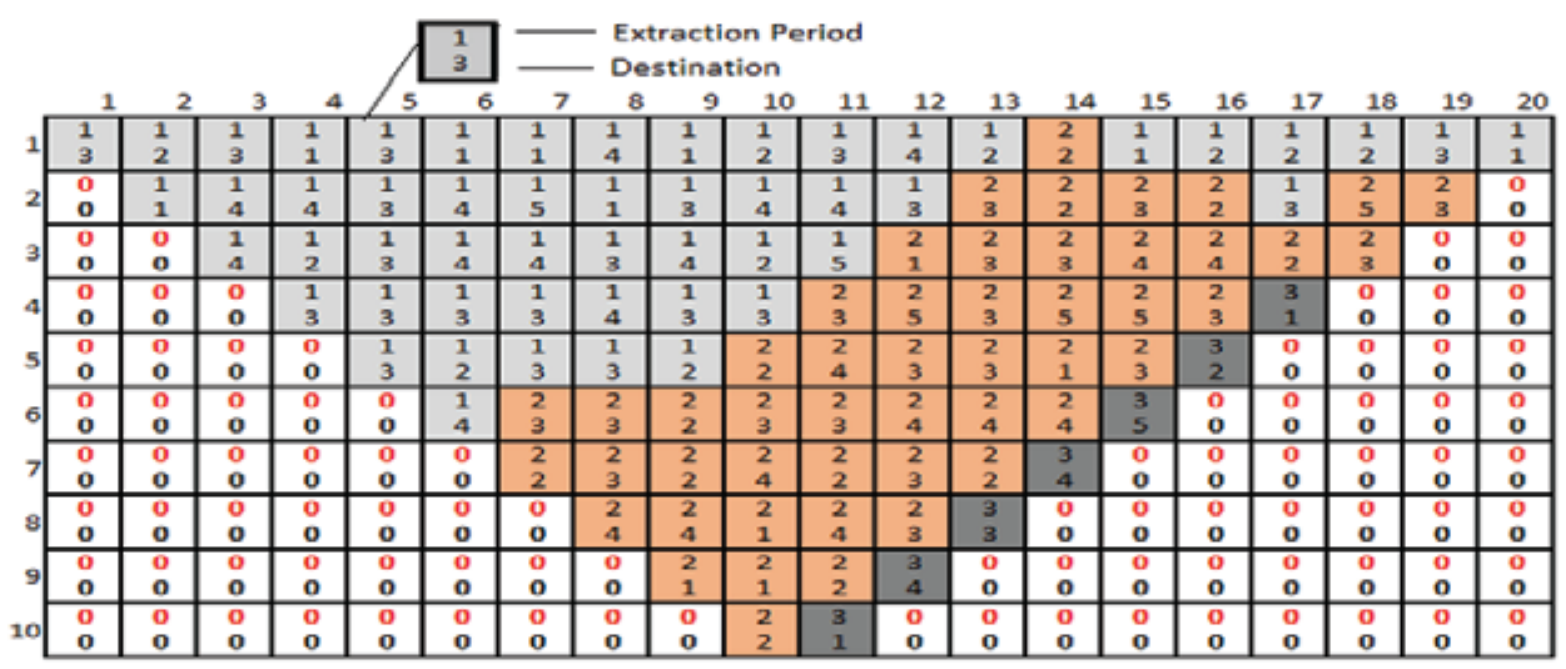

Fig. 9. The result of the model in 5thscenario (highest NPV) 
condition to first case (four destinations), the only difference between them is the number of destination for mine product. The result of this case is shown in Table VI.

Table V. Scenarios in the case of one destination

\begin{tabular}{cccc}
\hline Scenario & COG (\%) & $\begin{array}{c}\text { Average grade } \\
\text { of Fe (\%) after } \\
\text { EU }\end{array}$ & $\begin{array}{c}\text { compatible } \\
\text { Destination }\end{array}$ \\
\hline 1 & - & 55.7 & No. 4 \\
2 & 52 & 56.2 & No. 3 \\
3 & 54 & 57.9 & No. 3 \\
4 & 56 & 59.08 & No. 2 \\
6 & 58 & 59.25 & No. 2 \\
\hline
\end{tabular}

Table VI. The results of case of one destination

\begin{tabular}{ccc}
\hline Scenario & COG $(\%)$ & NPV $(\$)$ \\
\hline 1 & - & $14,307,966$ \\
\hline 2 & 52 & $14,349,048$ \\
\hline 3 & 54 & $15,015,139$ \\
\hline 4 & 56 & $20,047,478$ \\
\hline 5 & 58 & $17,537,815$ \\
\hline 6 & 60 & $17,229,100$ \\
\hline
\end{tabular}

In Table VI, it could be seen that scenario No. 4 has the highest NPV in that is $20,047,475 \$$.

Comparing the results of two case shows that the NPV of the project in most scenarios of one destination is lower than the case that four destinations are considered for mine product. The differences are shown in Fig. 10.

In higher COGs, more blocksare sent to the EU and consequently the average grade of Fe will be increased, but in Fig. 10 it could be seen that total NPV of the project will not increase by sending more blocks to EU. The highest NPV occurred in COG 52\% in case of four destinations and $56 \%$ in case of one destination. In the case of four destinations, the highest NPV (scenario No. 2) is about 25\% more than the highest NPV in the case of one destination (scenario No. 4).

As a result, when the number of considered destination for mine product increases, there is an opportunity to used

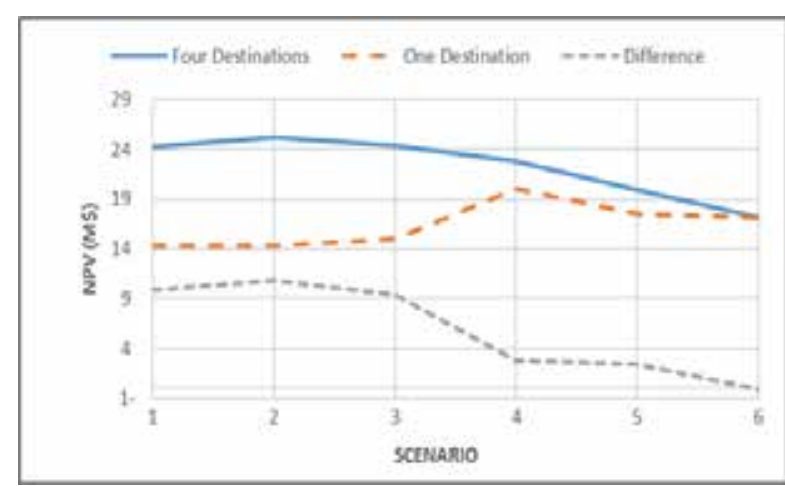

Fig. 10. NPVs of different scenarios in two cases

different blocks in blending plans to achieve a higher NPV. Considering more selling opportunity (i.e. destination) for mine product helps to have more flexibility in production planning. It means that if only one destination considered for extracted blocks, the mine planner has only one opportunity for using the block.But, if the number of destinations increases, consequently the opportunity of using blocks in different blending plans will be increased. In this condition, the mine plannerscan blend different ore block to produce a broad range of product.

\section{Conclusion}

Production scheduling determines which blocks to be extracted in each period considering operational constraints. Generally, the goal of production scheduling is to maximize NPV of the project. In the case of some ore minerals such as iron ore, coal, and industrial material, blending is required to provide a product that meets customers' requirements. Blending is essential for keeping mine output as close as possible to consumer's inquiries. In this case, of high-grade iron ores, which the minerals called direct shipping ores; it is possible to consider more than one destination with different quality and quantity requirements for products. In this paper, the modeling and scheduling optimization for iron ore blending is investigated by considering four destinations for mine product. The proposed model is a mixed integer programming and the objective function is to maximize the total NPV of the project incorporate with satisfying blending requirements of all destinations.

The model also considers the impact of enrichment unit in production scheduling and is solved for six different scenarios, in order to determine the best blend for the whole project and finding a suitable destination for ore blocks in each mining period. In this case, according to the number of destinations, different blending plans are used. 
All the scenarios are solved in the case that only one destination is considered for mine product. There is a noticeable difference between NPVs of the case with one destination and the case that four destinations are considered. The highest NPV in the case with four destinations is about $25 \%$ more than the highest NPV of the case with one destination.

Using proposed model,it is possible to construct a plan, not just with a single product, but taking into account that a block can be blended with other blocks to make one of many alternative final products and send the block to the destination that achieves the more benefit and consequently maximum NPV for mine project.

\section{References}

Asad MWA (2011), A heuristic approach to long-range production planning of cement quarry operations, Journal of Production Planning \& Control 22: 353-364. DOI: 10.1080/09537287.2010.484819

Askari-Nasab H, Eivazy H, Tabesh M and Badiozamani MM (2011), A mathematical programming model for open pit short-term production scheduling, SME Annual Meeting, pp 1-8.

Caccetta L and Giannini LM (1986), Optimization Techniques for the Open Pit Limit Problem, Proc. Australia's. Inst. Min. Metall. Vol. 291, pp 57-63.

Chanda EKC, Dagdalen K (1995), Optimal blending of mine production using goal programming and interactive graphics systems, International Journal of Surface Mining, Reclamation and Environment 9: 203-208. DOI: $10.1080 / 09208119508964748$

Denby B, Schofield D and Bradford S (1991), Neural Network Applications in Mining Engineering, Department of Mineral Resources Engineering Magazine, University of Nottingham, pp 13-23.

Dimitrakopoulos R and Ramazan S (2008), Stochastic integer programming for optimising long term production schedules of open pit mines: Methods, application and value of stochastic solutions, Mining Technology 117(4): 155-160. DOI: 10.1179/174328609X417279

Eivazy H and Askari-Nasab H (2012), A mixed integer linear programming model for short-term open pit mine operation scheduling, Mining Technology 121: 97-108. DOI: 10.1179/1743286312Y.0000000006
Fytas K and Calder P (1986), A computerized model of open pit short and long range production scheduling. proceeding of $19^{\text {th }}$ APCOM, pp 109-119.

Gholamnejad J, Osanloo M and Khoram E (2008), A chance constrained integer programming model for open pit long-term production planning. Transaction A: Basic, International Journal of Engineering 21: 407-418.

Goodfellow RC and Dimitrakopoulos R (2016), Global optimization of open pit mining complexes with uncertainty, Journal of Applied soft computing 40: 292-304. DOI: 10.1016/j.asoc.2015.11.038

Jamshidi M and Osanloo M (2016), Determination of block economic value in multi-element deposits. $6^{\text {th }}$ International Conference in Computer Applications in the Minerals Industries. Istanbul, Turkey.

Jelvez E, Morales N, Penard PN, Peypouquet J and Reyes P (2016), Aggregation heuristic for the open-pit block scheduling problem, European Journal of Operating Research 249: 1169-1177. DOI: 10.1016/j.ejor.2015.10.044

Kumral M (2003), Application of chance-constrained programming based on multi-objective simulated annealing to solve a mineral blending problem, Journal of Engineering Optimization 35: 661-673. DOI: $10.1080 / 03052150310001614837$

Kumral M and Dowd PA (2002), Short term mine production scheduling for industrial mineral using multi objective simulated annealing In: Proceeding of $30^{\text {rd }}$ APCOM.731-737.

L'Heureux G, Gamache M and Soumis F (2013), Mixed integer programming model for short-term planning in open-pit mines, Mining Technology 122(2): 101-109. DOI: $10.1179 / 1743286313$ Y.0000000037

Lamghari A and Dimitrakopoulos R (2012), A diversified tabu search approach for the open-pit mine production scheduling problem with metal uncertainty, European Journal of Operational Research 222(3): 642-652. DOI: 10.1016/j.ejor.2012.05.029

Matamoros M and Dimitrakopoulos R (2016), Stochastic short-term mine production schedule accounting for fleet allocation, operational considerations and blending restrictions, European Journal of Operational Research 255: 911-921. DOI: 10.1016/j.ejor.2016.05.050 
Mohammadi S, Kakaie R, Ataei M and Pourzamani E (2017), Determination of the optimum cut-off grades and production scheduling in multi-product open pit mines using imperialist competitive algorithm (ICA), Resources Policy 51: 39-48. DOI: 10.1016/j.resourpol.2016.11.005

Montiel L and Dimitrakopoulos (2015), Optimizingminingcomplexes with multiple processing and transportation alternatives: Anuncertaintybasedapproach, European Journal of Operational Research 247: 166-178. DOI: 10.1016/j.ejor.2015.05.002

Moren E, Rezakhah M, Newman A and Ferreira F (2017), Linear models for stockpiling in open-pit mine production scheduling problems, European Journal of Operational Research 260: 212-221. DOI: 10.1016/j.ejor.2016.12.014

Osanloo M and Rahmanpour M (2017), Optimizing short-term production plan using a portfolio optimization model, REM-International Engineering Journal $\quad$ 70(1): $\quad 109-116 . \quad$ DOI: 10.1590/0370-44672016700071

Peng FF, Walters AD, Geer MR and Leonard JW (1979), Evaluation and prediction of optimum cleaning results, $4^{\text {th }}$ Ed. Coal Preparation, The American institute of mining, metallurgical and petroleum engineers,

Peralta A (1991), Analysis of the blending problem in open pit production scheduling, Dissertation, Queen's University, Canada, p 207.

Rahman S and Asad MWA (2010), A mixed integer linear programming model for short range production scheduling of cement quarry operations, Asia Pacific Journal of Operating Research 27: 315-333. DOI: $10.1142 / \mathrm{S} 0217595910002727$

Rahmanpour M and Osanloo M (2012), Pit limit determination considering blending requirements. in Proceeding MPES, pp 564-575.

Samanta B and Bhattacherjee A (2005), A genetic algorithms approach for grade control planning in a bauxite deposit. in Proceeding APCOM, pp 334-342.

Sari YA and Kumral M (2015), Mine production scheduling for poly-metallic mineral deposits: extension to multiple processes. International Journal of Planning and Scheduling 2: 134-153. DOI: 10.1504/IJPS.2015.072107
Smith ML (2001), Integrating conditional simulation and stochastic programming: an application in production scheduling, Proceeding of APCOM, pp 203-208.

Smith ML and Wicks SJ (2014), Medium-term production scheduling of the lumwana mining complex, Interfaces 44(2): 176-194. DOI: 10.1287/inte.2014.0737

Souza MJF, Coelho IM, Ribas S, Santos HG and Merschmann LHC (2010), A hybrid heuristic algorithm for the open-pit-mining operational planning problem, European research 27: 1041-1051. DOI: 10.1016/j.ejor.2010.05.031

Sundar DK and Acharya D (1995), Blast schedule planning and shift wise production scheduling of an opencast iron ore mine, Journal of Computers Industrial Engineering 28: 927-932. DOI: 10.1016/0360-8352(94)00221-8

Technical Report (2015), Short term production planning of Tapeh Qermez iron ore mine, Kavoshgaran Consulting Engineering, p 61.

Temeng VA, Francis OO and Frendewey JO (1997), Real-time truck dispatching using a transportation algorithm, International Journal of Surface Mining, Reclamation and Environment 11: 203-207. DOI: 10.1080/09208119708944093

Towhidi N and Vaghar R (1998), Preparation of iron and steel charge material, $3^{\text {rd }}$ Ed. University of Tehran press, p 909. DOI: 10.1016/S0379-6779(97)80256-1

United States Geological Survey (2016), Mineral Commodity Summaries. DOI: 10.3133/70194932

Vujic S, Benovic T, Miljanovic I, Hudaj M, Milutinovic A and Pavlovic P (2011), Fuzzy linear model for production optimization of mining systems with multiple entities, International Journal of Minerals, Metallurgy and Materials 18: 633-644.

White W and Olson J (1986), Computer-Based Dispatching in Mines with Concurrent Operating Objectives, Journal of Mining Engineering 38: 1045-1054.

Zuckerberg M, Vanderiet J, Malajczuk W and Stone P (2011), Optimal life-of-mine scheduling for a bauxite mine, Journal of Mining Science 47: 158-165. 